\begin{tabular}{ll}
\hline \hline MINING AND METALLURGY INSTITUTE BOR & ISSN: 2334-8836 (Štampano izdanje) \\
UDK: 622 & ISSN: 2406-1395 (Online) \\
\hline \hline
\end{tabular}

Danijela Vujić, Dragiša Stanujkić*, Snežana Urošević, ${ }^{* *}$, Darjan Karabašević****

\title{
AN APPROACH TO LEADER SELECTION IN THE MINING INDUSTRY BASED ON THE USE OF WEIGHTED SUM PREFERRED LEVELS OF THE PERFORMANCES METHOD
}

\begin{abstract}
Today, more attention is paid to the leadership and leaders in the mining industry. Leadership and leaders have a key role in creating a sustainable competitive advantage of enterprises. Leaders initiate changes and create conditions for higher quality products and services and contribute to the improvement of market position of the company. Enterprises in their operations seek to ensure personnel that possess leadership skills due to their belief that such people can provide the additional value to their organizations. Bearing in mind the importance of the leaders for organization, therefore this manuscript is aimed to the selection of leaders in the mining industry based on the use of multiple-criteria decisionmaking methods (MCDM). The proposed approach for selection of leaders is based on the use of the SWARA method and a weighted sum preferred levels of performances approach (WS PLP). The usability and efficiency of the proposed approach is considered on the conducted empirical example.

Keywords: leadership; leaders; mining industry; MCDM; SWARA; WS PLP
\end{abstract}

\section{INTRODUCTION}

Proper decision making and adoption of decisions having the function of continuous improvements in the field of work contributes to the success of sustainable business operations of mining companies [8]. Therefore, one of the key decisions that lie on the management of mining companies is the selection of personnel/people. People with their skills, knowledge and personal capabilities are very significant resource of any organization. The achievement of organizational goals in a harsh business environment depends on them and their inventiveness, innovation, information and most important motivation; further, Urošević et al. [14] especially emphasizes importance of moti vation and satisfaction of employees of the organization.

Taking into account that the strategic and organizational solutions become increasingly complex and demanding, there is a need that the top management of the company should replace its traditional focus on strategy and structure towards managing people and processes. Today the critical strategic requirements are related not only to finde the most appropriate structural solutions, but to finde an organizational design that will allow usage of all the potential of employees and to motivate the entire organization, in order to be ready to work in a complex and dynamic environment [1].

\footnotetext{
* Faculty of Management Zaječar, John Naisbitt University Belgrade, Park Šuma “Kraljevica” bb, 19000 Zaječar, Serbia

** Technical Faculty in Bor, University of Belgrade, Vojske Jugoslavije 12, 19210 Bor, Serbia

${ }^{* * *}$ Faculty for Applied Management, Economics and Finance, Business Academy University, Jevrejska 24, 11000 Belgrade, Serbia.e-mail: darjankarabasevic@gmail.com
} 
Therefore, in modern business organizations, increasing attention is given to the very concept of teamwork and leadership. Leadership as a specialized management discipline is becoming an inevitable factor that affects the performance of entire business. Leadership is a phenomenon that in recent decades, with a high degree of intensity is continuously explored. As a result of this research, there are numerous and varied definitions of the concept of leadership. Higgins [3] defines leadership as the "process of making choices about how to act with people in giving orders for influencing on them and then of transformation of those choices into actions". Kotter [6] for leadership says that represents the art of mobilezing others which want to struggle for realization the common aspirations, whereas Chemers [2] leadership define as a process of social influence in which a person can enlist the aid and support of others in the fulfilment of a common goal. Yukl [15] points out that leadership is a process of influence that affect the interpretation of events by the followers, selection of objectives for a group or organization, organization of work activities in order to achieve the objectives, the maintenance of cooperative relations and teamwork, as well as the provision of support and cooperation from people outside the group or organization. Northouse [10] states that leadership is a process whereby an individual influences the members of the group in order to achieve the common objective. As it can be seen from previous definitions, leadership can be viewed as a phenomenon that is bound to change, also, leadership is a process of influence on a group of people / followers in order to achieve a specific goal.

In the literature on leadership, the terms such as leader and manager are often used. Leadership is important for management, but it does not mean that every manager has the ability of a leader i.e. the ability to motivate others in the organization. Kotter [6] states that the essence of the distinction between these two notions is in differentia- ting of tasks of leaders and managers. Leader is the creator of the mission and leader is a visionary of the organization, by contrast, the task of the manager is to realize this vision in practice.

Multiple - criteria decision - making (MCDM) is often used as a tool for solving a wide range of complex problems. In the simplest sense, MCDM can be defined as the selection of an alternative from the set of available alternatives. Rapid development of the MCDM field has caused a creation of many methods, therefore, a good overview and comparisons of some of them are given by Mardani et al. [7] and Turskis and Zavadskas [13]. It is also important to point out that MCDM methods are applied for personnel selection problems, such as: selection of candidates in the mining industry based on the application of the SWARA and the MULTIMOORA methods [4], and the leadership competency evaluation and selection of leader by integration of fuzzy Shannon's entropy and VIKOR methods [9], and so on.

For all the above-mentioned reasons, the rest of this paper is organized as follows: In Section 1 Introductory considerations are presented. In Section 2, the SWARA method is presented in details. The WS PLP approach is considered in Section 3. In Section 4 , a framework for the selection of the alternatives based on the use of the WS PLP and the SWARA methods is given. In Section 5, an empirical illustration of leader selection is considered, with the aim to explain in detail the proposed methodology. Finally, the conclusions are given at the end of the manuscript.

\section{SWARA METHOD}

The SWARA method was proposed by Kersuliene et al. [5]. Similarly to the wellknown AHP method, the SWARA methods can be used to determine the weight of criteria as well as to completely solve MCDM problems. However, compared with the AHP method, the SWARA method requires 
the significantly lower number of pairwise comparisons.

Based on Kersuliene et al. [5] and Stanujkic et al. [12], the computational procedure of the ordinary SWARA method can be shown through the following steps:

Step 1. Determine the set of the relevant evaluation criteria and sort them in descending order, based on their expected significances.

Step 2. Starting from the second criterion, determine the relative importance $s_{j}$ of the criterion $j$ in relation to the previous $(j-1)$ criterion, and do so for each particular criterion.

Step 3. Determine the coefficient $k_{j}$ as follows:

$$
k_{j}=\left\{\begin{array}{cc}
1 & j=1 \\
s_{j}+1 & j>1
\end{array} .\right.
$$

Step 4. Determine the recalculated weight $q_{j}$ as follows:

$$
q_{j}=\left\{\begin{array}{cc}
1 & j=1 \\
\frac{q_{j-1}}{k_{j}} & j>1
\end{array} .\right.
$$

Step 5. Determine the relative weights of the evaluation criteria as follows:

$$
w_{j}=\frac{q_{j}}{\sum_{k=1}^{n} q_{k}},
$$

where $w_{j}$ denotes the relative weight of the criterion $j$.

\section{WS PLP APPROACH}

Based on the Weighted Sum method, Stanujkic and Zavadskas [11] proposed the WS PLP approach. The basic idea of the WS PLP approach can be shown as follows:

$$
S_{i}^{\prime}=\sum_{j=1}^{n} w_{j} r_{i j}-\gamma c_{i},
$$

where $S_{i}^{\prime}$ denotes the adjusted overall performance rating of the alternative $i, c_{i}$ is the compensation coefficient; $c_{i}>0, \gamma$ is the coefficient, and $\gamma \in[0,1]$.

In this approach, the compensation coefficient is introduced with the aim to provide adequate ratios between the greatest possible value of $S_{i}$ and better matching with preferred performance ratings given by decision makers. According to Stanujkic and Zavadskas [11], the compensation coefficient should be calculated as follows:

$$
c_{i}=\lambda d_{i}^{\max }+(1-\lambda) \bar{S}_{i}^{*},
$$

with:

$$
\begin{aligned}
& d_{i}^{+\max }=\max _{i} r_{i j} w_{j} ; \quad r_{i j}>0, \\
& \bar{S}_{i}^{+}=\frac{S_{i}^{+}}{n_{i}^{+}}
\end{aligned}
$$

and

$$
\bar{S}_{i}^{*}=\frac{S_{i}^{+}}{n_{i}^{*}},
$$

where: $d_{i}^{\max }$ denotes the maximum weighted normalized distance of alternative $i$ to the preferred performance ratings of all the criteria, so that $r_{i j}>0 ; \bar{S}_{i}^{*}$ denotes the average performance ratings achieved on the basis of criteria, so that $r_{i j} \geq 0 ; n_{i}^{+}$denotes the number of criteria of alternative $i$, so that $r_{i j} \geq 0 ; \lambda$ is coefficient, $\lambda \in[0,1]$ and is usually set at 0.5 .

\subsection{Computational Procedure of the WS PLP Approach}

Based on the above considerations, the computational procedure of the WS PLP approach for a MCDM problem containing $m$ alternatives and $n$ criteria can precisely be expressed by using the following steps [11]: 
Step 1. Evaluate the alternatives in relation to the selected set of criteria.

Step 2. Define the preferred performance ratings for each criterion. In this step, the decision maker sets the preferred performance ratings for evaluation criteria, thus forming the virtual alternative $A_{0}=\left\{x_{01}, x_{02}, \ldots, x_{0 n}\right\}$. If the decision maker does not have preferences for any criterion, it should be determined as follows:

$$
x_{0 j}=\left\{\begin{array}{l}
\max _{i} x_{i j} \mid j \in \Omega_{\max } \\
\min _{i} x_{i j} \mid j \in \Omega_{\min }
\end{array},\right.
$$

where $x_{0 j}$ denotes the preferred performance rating of criterion $j$.

Step 3. Construct a normalized decision matrix. The normalized performance ratings should be calculated as follows:

$$
r_{i j}=\frac{x_{i j}-x_{0 j}}{x_{j}^{+}-x_{j}^{-}},
$$

where:

$$
\begin{aligned}
& x_{j}^{+}=\left\{\begin{array}{l}
\max _{i} x_{i j} \mid j \in \Omega_{\max } \\
\min _{i} x_{i j} \mid j \in \Omega_{\min }
\end{array},\right. \text { and } \\
& x_{j}^{-}=\left\{\begin{array}{l}
\min _{i} x_{i j} \mid j \in \Omega_{\max } \\
\max _{i} x_{i j} \mid j \in \Omega_{\min }
\end{array}\right.
\end{aligned}
$$

Step 4. Calculate the overall performance rating for each alternative, as follows:

$$
S_{i}=\sum_{j=1}^{n} w_{j} r_{i j}
$$

where $S_{i}$ denotes the overall performance rating of alternative $i$

Step 5. Calculate the compensation coefficient for all the alternatives with $S_{i}>0$ by applying Eq. (5).

Step 6. Calculate the adjusted performance rating for all the alternatives with $S_{i}>0$, as follows:

$$
S_{i}^{\prime}=S_{i}-\gamma c_{i}
$$

where the decision maker can reduce, or even eliminate, the impact of compensation coefficient by varying the values of coefficient $\gamma$.

Step 7. Rank the alternatives and select the most efficient one. The considered alternatives are ranked by ascending $S_{i}^{\prime}$.

\section{FRAMEWORK BASED ON THE USE OF THE SWARA METHOD AND WS PLP APPROACH}

The framework based on the SWARA and WS PLP can accurately be expressed through the following phases and the corresponding steps.

Phase I - Form a team of experts who will carry out the evaluation, determine the set of available alternatives and form the set of evaluation criteria.

Phase II - Determine the relevance and weights of evaluation criteria. In the proposed approach, the SWARA method is used for determining the weights of evaluation criteria, as shown in Section 2.

Phase III - Evaluate the alternatives. The evaluation of alternatives is based on the application of the WS PLP approach, as shown in Section 3.

The five-point Likert Scale, shown in Table 1, is proposed for evaluating the alternatives with respect to the selected evaluation criteria.

Table 1 Ratings for evaluating criteria

\begin{tabular}{cl}
\hline Ratings & Meaning \\
\hline 1 & Excellent \\
\hline 2 & Good \\
\hline 3 & Average \\
\hline 4 & Fair \\
\hline 5 & Poor
\end{tabular}

In this phase, applying the first part of the WS PLP approach, each expert involved in the evaluation calculates his/her own adjusted overall ratings for the considered 
alternatives, on which basis the corresponding ranking orders of alternatives is formed.

Phase IV - Selection of the most appropriate alternative. As a result of conducting the previous phase, the $K$ ranking orders of alternatives are obtained.

Based on the theory of ordinal dominance, the alternative appearing in the first position the largest number of times is potentially the most appropriate one. However, in some cases, when it is not so easy to determine the dominant alternative, the evaluation process should be sent back, usually at the step 6 in phase IV; but, in rare cases, it can be put back to the beginning of phase IV, or even beginning of phase III.

\section{AN EMPIRICAL ILLUSTRATION OF THE PROPOSED APPROACH OF LEADER SELECTION}

In this section, in order to briefly demonstrate the efficiency and usability of theabove considered approach, an example of selection the leaders/candidates in the mi- ning industry is considered. Suppose that the human resources decision makers (HRMs) have evaluated the criteria and competences for the total of five preselected leaders / candidates.

The team of the HRMs have used seven criteria adopted from Moradi et al. [9] for further evaluation of leaders, as follows:

- Follower Retention $\left(C_{1}\right)$,

- Follower - Organizational Citizenship Behaviour (OCB) $\left(C_{2}\right)$,

- Productivity/ performance outcomes $\left(C_{3}\right)$,

- Corporate Sustainability $\left(C_{4}\right)$,

- Leader Motivation $\left(C_{5}\right)$,

- Leader Relationship $\left(C_{6}\right)$, and

- Leader Resilience $\left(C_{7}\right)$.

After that, each of three HRMs determines weights of evaluation criteria using the SWARA method. The opinions of HRMs and weights of are shown in Tables 2, 3 and 4 .

Table 2 The opinions of the first of the three HRMs and weights of criteria

\begin{tabular}{ccccc}
\hline Criteria & $\boldsymbol{s}_{\mathbf{j}}$ & $\boldsymbol{k}_{\mathbf{j}}$ & $\boldsymbol{q}_{\mathbf{j}}$ & $\boldsymbol{w}_{\mathbf{j}}$ \\
\hline$C_{1}$ & & 1 & 1 & 0.18 \\
\hline$C_{2}$ & 0.9 & 1.1 & 0.91 & 0.17 \\
\hline$C_{3}$ & 1 & 1 & 0.91 & 0.17 \\
\hline$C_{4}$ & 0.75 & 1.25 & 0.73 & 0.13 \\
\hline$C_{5}$ & 1 & 1 & 0.73 & 0.13 \\
\hline$C_{6}$ & 0.8 & 1.2 & 0.61 & 0.11 \\
\hline$C_{7}$ & 1 & 1 & 0.61 & 0.11 \\
\hline & & & 5.48 & 1.00
\end{tabular}

Table 3 The opinions of the second of the three HRMs and weights of criteria

\begin{tabular}{ccccc}
\hline Criteria & $\boldsymbol{s}_{\mathbf{j}}$ & $\boldsymbol{k}_{\mathbf{j}}$ & $\boldsymbol{q}_{\mathbf{j}}$ & $\boldsymbol{w}_{\mathbf{j}}$ \\
\hline$C_{1}$ & & 1 & 1 & 0.16 \\
\hline$C_{2}$ & 1 & 1 & 1.00 & 0.16 \\
\hline$C_{3}$ & 0.9 & 1.1 & 0.91 & 0.15 \\
\hline$C_{4}$ & 0.85 & 1.15 & 0.79 & 0.13 \\
\hline$C_{5}$ & 1.1 & 0.9 & 0.88 & 0.14 \\
\hline$C_{6}$ & 1 & 1 & 0.88 & 0.14 \\
\hline$C_{7}$ & 0.9 & 1.1 & 0.80 & 0.13 \\
\hline & & & 6.25 & 1.00 \\
\cline { 3 - 4 } & & &
\end{tabular}


Table 4 The opinions of the third of the three HRMs and weights of criteria

\begin{tabular}{ccccc}
\hline Criteria & $\boldsymbol{s}_{\mathbf{j}}$ & $\boldsymbol{k}_{\mathbf{j}}$ & $\boldsymbol{q}_{\mathbf{j}}$ & $\boldsymbol{w}_{\mathbf{j}}$ \\
\hline$C_{1}$ & & 1 & 1 & 0.18 \\
\hline$C_{2}$ & 1 & 1 & 1.00 & 0.18 \\
\hline$C_{3}$ & 1 & 1 & 1.00 & 0.18 \\
\hline$C_{4}$ & 0.8 & 1.2 & 0.83 & 0.15 \\
\hline$C_{5}$ & 0.8 & 1.2 & 0.69 & 0.12 \\
\hline$C_{6}$ & 0.7 & 1.3 & 0.53 & 0.10 \\
\hline$C_{7}$ & 1 & 1 & 0.53 & 0.10 \\
\hline & & & 6.25 & 1.00 \\
\cline { 3 - 4 }
\end{tabular}

In the next Phase III, the HRMs made an evaluation of the preselected leaders in relation to the set of evaluation criteria. The obtained ratings, as well as the weights and preferred ratings, obtained from the three HRMs are given in Tables 5, 6 and 7.

Table 5 The ratings, weighting and preferred ratings obtained from the first of the three HRMs

\begin{tabular}{|c|c|c|c|c|c|c|c|}
\hline Criteria & $C_{1}$ & $C_{2}$ & $C_{3}$ & $C_{4}$ & $C_{5}$ & $C_{6}$ & $C_{7}$ \\
\hline$w_{j}$ & 0.18 & 0.17 & 0.17 & 0.13 & 0.13 & 0.11 & 0.11 \\
\hline $\mathrm{A}^{*}$ & 4 & 4 & 4 & 4 & 3 & 3 & 3 \\
\hline$A_{1}$ & 4 & 4 & 4 & 4 & 3 & 4 & 4 \\
\hline$A_{2}$ & 4 & 5 & 4 & 4 & 4 & 2 & 2 \\
\hline$A_{3}$ & 5 & 4 & 5 & 3 & 3 & 5 & 4 \\
\hline$A_{4}$ & 4 & 3 & 3 & 3 & 4 & 3 & 3 \\
\hline$A_{5}$ & 4 & 4 & 3 & 3 & 3 & 5 & 5 \\
\hline
\end{tabular}

Table 6 The ratings, weighting and preferred ratings obtained from the second of the three HRMs

\begin{tabular}{|c|c|c|c|c|c|c|c|}
\hline Criteria & $C_{1}$ & $C_{2}$ & $C_{3}$ & $C_{4}$ & $C_{5}$ & $C_{6}$ & $C_{7}$ \\
\hline$w_{j}$ & 0.16 & 0.16 & 0.15 & 0.13 & 0.14 & 0.14 & 0.13 \\
\hline$A^{*}$ & 4 & 4 & 3 & 3 & 3 & 4 & 4 \\
\hline$A_{1}$ & 4 & 3 & 3 & 2 & 2 & 3 & 3 \\
\hline$A_{2}$ & 4 & 4 & 4 & 3 & 3 & 3 & 4 \\
\hline$A_{3}$ & 3 & 3 & 4 & 3 & 2 & 3 & 4 \\
\hline$A_{4}$ & 3 & 3 & 4 & 4 & 2 & 3 & 3 \\
\hline$A_{5}$ & 4 & 4 & 4 & 4 & 4 & 4 & 4 \\
\hline
\end{tabular}


Table 7 The ratings, weighting and preferred ratings obtained from the third of the three HRMs

\begin{tabular}{|c|c|c|c|c|c|c|c|}
\hline Criteria & $C_{1}$ & $C_{2}$ & $C_{3}$ & $C_{4}$ & $C_{5}$ & $C_{6}$ & $C_{7}$ \\
\hline$w_{j}$ & 0.18 & 0.18 & 0.18 & 0.15 & 0.12 & 0.10 & 0.10 \\
\hline $\mathrm{A}^{*}$ & 4 & 3 & 4 & 3 & 3 & 3 & 3 \\
\hline$A_{1}$ & 4 & 3 & 4 & 3 & 4 & 2 & 2 \\
\hline$A_{2}$ & 4 & 2 & 3 & 3 & 3 & 3 & 3 \\
\hline$A_{3}$ & 5 & 3 & 3 & 2 & 3 & 3 & 3 \\
\hline$A_{4}$ & 3 & 3 & 3 & 4 & 3 & 4 & 4 \\
\hline$A_{5}$ & 4 & 3 & 4 & 4 & 3 & 3 & 3 \\
\hline
\end{tabular}

The normalized decision matrix and weighted normalized decision matrix formed on the basis of the responses obtained from first of the three HRMs are presented in $\mathrm{Ta}$ bles 8 and 9 .

Table 8 The normalized decision matrix based on the responses obtained from the first of the three HRMs

\begin{tabular}{cccccccc}
\hline Criteria & $\boldsymbol{C}_{\boldsymbol{1}}$ & $\boldsymbol{C}_{\mathbf{2}}$ & $\boldsymbol{C}_{\mathbf{3}}$ & $\boldsymbol{C}_{\mathbf{4}}$ & $\boldsymbol{C}_{\mathbf{5}}$ & \multicolumn{1}{c}{$\boldsymbol{C}_{\mathbf{6}}$} & \multicolumn{1}{c}{$\boldsymbol{C}_{\boldsymbol{7}}$} \\
\hline$A_{1}$ & 0.00 & 0.00 & 0.00 & 0.00 & 0.00 & 0.33 & 0.33 \\
\hline$A_{2}$ & 0.00 & 0.50 & 0.00 & 0.00 & 1.00 & -0.33 & -0.33 \\
\hline$A_{3}$ & 1.00 & 0.00 & 0.50 & -1.00 & 0.00 & 0.67 & 0.33 \\
\hline$A_{4}$ & 0.00 & -0.50 & -0.50 & -1.00 & 1.00 & 0.00 & 0.00 \\
\hline$A_{5}$ & 0.00 & 0.00 & -0.50 & -1.00 & 0.00 & 0.67 & 0.67 \\
\hline
\end{tabular}

Table 9 The weighted normalized decision matrix based on the responses obtained from the first of the three experts

\begin{tabular}{cccccccr}
\hline Criteria & $\boldsymbol{C}_{\mathbf{1}}$ & $\boldsymbol{C}_{\mathbf{2}}$ & $\boldsymbol{C}_{\mathbf{3}}$ & $\boldsymbol{C}_{\mathbf{4}}$ & $\boldsymbol{C}_{\mathbf{5}}$ & $\boldsymbol{C}_{\mathbf{6}}$ & $\boldsymbol{C}_{\mathbf{7}}$ \\
\hline$A_{1}$ & 0.00 & 0.00 & 0.00 & 0.00 & 0.00 & 0.04 & 0.04 \\
\hline$A_{2}$ & 0.00 & 0.08 & 0.00 & 0.00 & 0.13 & -0.04 & -0.04 \\
\hline$A_{3}$ & 0.18 & 0.00 & 0.08 & -0.13 & 0.00 & 0.07 & 0.04 \\
\hline$A_{4}$ & 0.00 & -0.08 & -0.08 & -0.13 & 0.13 & 0.00 & 0.00 \\
\hline$A_{5}$ & 0.00 & 0.00 & -0.08 & -0.13 & 0.00 & 0.07 & 0.07 \\
\hline
\end{tabular}

In the same manner, the normalized decision matrix and the weighted normalized decision matrix for the second and the third experts are calculated. The calcu- lation details obtained by using the WS PLP approach, based on responses three HRMs, are shown in Tables 10, 11, 12 and 13. 
Table 10 The calculation details obtained based on the responses of the first of the three HRMs

\begin{tabular}{cccccccc}
\hline & $\boldsymbol{S}_{\mathbf{i}}$ & Ranks & $d_{i}^{+\max }$ & $n_{i}^{*}$ & $S_{i}^{*}$ & $S_{i}^{\prime}$ & Final ranks \\
\hline$A_{1}$ & 0.07 & 3 & 0.04 & 7 & 0.07 & 0.01 & 5 \\
\hline$A_{2}$ & 0.14 & 2 & 0.13 & 5 & 0.22 & 0.04 & 2 \\
\hline$A_{3}$ & 0.24 & 1 & 0.18 & 6 & 0.38 & 0.06 & 1 \\
\hline$A_{4}$ & -0.17 & 5 & 0.13 & 4 & 0.13 & 0.03 & 3 \\
\hline$A_{5}$ & -0.07 & 4 & 0.07 & 5 & 0.15 & 0.03 & 4 \\
\hline
\end{tabular}

Table 11 The calculation details obtained based on the responses of the second of the three HRMs

\begin{tabular}{cccccccc}
\hline & $\boldsymbol{S}_{\mathbf{i}}$ & Ranks & $d_{i}^{+\max }$ & $n_{i}^{*}$ & $S_{i}^{*}$ & $S_{i}^{\prime}$ & Final ranks \\
\hline$A_{1}$ & -0.56 & 5 & 0.00 & 2 & 0.00 & 0.00 & 5 \\
\hline$A_{2}$ & 0.00 & 2 & 0.15 & 6 & 0.15 & 0.02 & 4 \\
\hline$A_{3}$ & -0.39 & 3 & 0.15 & 3 & 0.15 & 0.05 & 2 \\
\hline$A_{4}$ & -0.45 & 4 & 0.15 & 2 & 0.21 & 0.10 & 1 \\
\hline$A_{5}$ & 0.28 & 1 & 0.15 & 7 & 0.28 & 0.04 & 3 \\
\hline
\end{tabular}

Table 12 The calculation details obtained based on the responses of the third of the three HRMs

\begin{tabular}{cccccccc}
\hline & $S_{\mathbf{i}}$ & Ranks & $d_{i}^{+\max }$ & $n_{i}^{*}$ & $S_{i}^{*}$ & $S_{i}^{\prime}$ & Final ranks \\
\hline$A_{1}$ & 0.03 & 2 & 0.12 & 5 & 0.12 & 0.02 & 2 \\
\hline$A_{2}$ & -0.36 & 5 & 0.00 & 5 & 0.00 & 0.00 & 5 \\
\hline$A_{3}$ & -0.16 & 4 & 0.09 & 5 & 0.09 & 0.02 & 3 \\
\hline$A_{4}$ & -0.10 & 3 & 0.07 & 5 & 0.17 & 0.03 & 1 \\
\hline$A_{5}$ & 0.07 & 1 & 0.07 & 7 & 0.07 & 0.01 & 4 \\
\hline
\end{tabular}

Table 13 The ranks obtained from the three HRMs obtained based on the WS PLP approach

\begin{tabular}{cccc}
\hline & $\boldsymbol{H R M}_{\mathbf{1}}$ & $\boldsymbol{H R M}_{\mathbf{2}}$ & $\boldsymbol{H R M}_{\mathbf{3}}$ \\
\hline$A_{1}$ & 3 & 2 & 5 \\
\hline$A_{2}$ & 2 & 4 & 4 \\
\hline$A_{3}$ & 1 & 5 & 3 \\
\hline$A_{4}$ & 5 & 1 & 1 \\
\hline$A_{5}$ & 4 & 3 & 2 \\
\hline
\end{tabular}

As it can be seen from Table 13, the leader labelled as $A_{4}$ ranks in the first position twice, on the basis of the opinions of experts $H_{R} M_{2}$ and $H R M_{3}$, whereas the leader $A_{3}$ ranks in the first position only once, on the basis of the opinion of the expert $H R M_{1}$.

Based on the theory of domination, it is evident that the leader labelled as $A_{4}$ is the most appropriate leader; and that is 
why the calculation process does not have to be re-done.

\section{CONCLUSIONS}

Human resource management through its core activities seeks to ensure to the organization a quality and dedicated leaders, who can cope with the effects of changes. In the area of leadership, the focus of global companies is put on early detection the candidates with leadership characteristics. Companies invest considerable efforts in organizing various programs in order to further direct and to develop their leadership skills.

The proposed approach for the selection of leader in the mining industry is based on the use of the SWARA method, the WS PLP approach and the theory of dominance.

In the proposed approach, each expert and/or decision maker involved in evaluation, sets the values for his/her preferred performance ratings of the selected evaluation criteria and determines his/her ranking list of the alternatives. After that, the alternative with the largest number of appearances in the first position in the ranking lists is declared the most acceptable alternative, or the most acceptable alternative(s) is (are) determined in the negotiation process if there is no dominant alternative.

Finally, the considered example of selection the leader in the mining industry has confirmed the applicability and usability of the proposed approach.

\section{REFERENCES}

[1] Aleksić A., Role and Importance of Leadership in the Conditions of Global Business, Sociology, 49(2) (2007) 145160 (in Serbian)

[2] Chemers M. M., An integrative Theory of Leadership. Lawrence Elrbaum Associates. Inc., Publishers, Mahwah, 1997 (in Serbian)
[3] Higgins J. M., The management Challenge: An Introduction to Management. Macmillan, New York, 1994.

[4] Karabasevic D., Stanujkic D., Urosevic S., Maksimovic M., Selection of Candidates in the Mining Industry Based on the Application of the SWARA and the MULTIMOORA Methods. Acta Montanistica Slovaca, 20(2) (2015) 116-124

[5] Keršuliene V., Zavadskas E. K., Turskis Z. Selection of Rational Dispute Resolution Method by Applying A New Step-Wise Weight Assessment Ratio Analysis (SWARA). Journal of Business Economics and Management, 11(2) (2010) 243-258

[6] Kotter J. P., Leading change. Harvard Business Press, 1996

[7] Mardani A., Jusoh A., MD Nor K., Khalifah Z., Zakwan N. Valipour A., Multiple Criteria Decision-Making Techniques and Their Applications A Review of the Literature from 2000 to 2014. Economic Research, 28(1) (2015) 516-571

[8] Miletić S., Paunković D., Bogdanović D., Evaluation of Sustainability Indicators for Decision-Making in Mining the Companies. Megatrend Review, 13(2) (2016) 83-96

[9] Moradi M., Maleki M., Pilehrood H. A., Leadership Competency Evaluation by Integration of Fuzzy Shannon's Entropy and VIKOR Methods. Global Journal of Advanced Research, 2(12) (2015) 1864-1870

[10] Northouse P. G., Introduction to Leadership: Concepts and practice. Sage Publications, 2014

[11] Stanujkic D., Zavadskas E. K., A Modified Weighted Sum Method Based on the Decision-Maker's Preferred Levels Of Performances. Studies in Informatics and Control, 24(4) (2015) 61-470

[12] Stanujkic D., Karabasevic D. Zavadskas E. K., A Framework for the 
Selection of a Packaging Design Based on the SWARA method. Engineering Economics 26(2) (2015) 181-187

[13] Turskis Z., Zavadskas E. K., Multiple Criteria Decision Making (MCDM) Methods in Economics: An Overview. Technological and Economic Development of Economy, 2 (2011) 397-427
[14] Urošević S., Milijić N., ĐorđevićMaljković N., Karabašević D., Indicators of Motivation and Employee Satisfaction in Public Enterprise: Case Study of PE 'Post of Serbia'. Industry, 44(3) (2016) 77-95

[15] Yukl G., Leadership in Organizations. Upper Saddle River, New Jersey, Prentice-Hall, 1998 